\title{
Age-related differences in outcome and process goal focus
}

\author{
Alexandra M. Freund and Marie Hennecke \\ University of Zurich, Zurich, Switzerland \\ Michaela Riediger \\ Max Planck Institute for Human Development, Berlin, Germany
}

Three studies report initial findings on age-related differences in goal focus. Study 1 compared younger ( $n=23,19-25$ years $)$ to older $(n=20,57-78$ years $)$ adults regarding their preference for representations of goals in terms of the means (process focus) or the associated outcomes (outcome focus). As expected, older adults chose process descriptors of goals more frequently than younger adults. Study 2 investigated the emotional consequences of goal focus. Whereas younger adults ( $n=49,18-25$ years) reported higher negative affect when they focused on the outcomes of a goal, older adults $(n=40,60-88$ years) reported higher positive affect when they focused on the process. Study 3, a 4-month longitudinal study, applied the distinction between process and outcome focus to the context of a personal goal in everyday life (starting to exercise). Older adults ( $n=46,55-78$ years) reported having a stronger process focus than younger adults ( $n=55,19-25$ years). Again, older adults were more likely to adopt a process than an outcome focus. For both age groups, process focus predicted positive goal-related development and affective well-being. In contrast, outcome focus was either not or negatively related to these outcomes.

Keywords: Goal focus; Process; Outcome; Age differences; Motivation.

Laypeople and motivation researchers agree that setting and pursuing goals has positive consequences. Goals give life meaning, direction, and contribute

Correspondence should be addressed to Alexandra M. Freund, University of Zurich, Department of Psychology, Binzmuehlestrasse 66, CH-8050 Zurich, Switzerland.

E-mail: freund@psychologie.uzh.ch.

The third study reported in this paper was conducted at and funded by the Max Planck Institute for Human Development, Berlin, Center for Lifespan Development.

We gratefully acknowledge the assistance of Iren Graf, Monika Chojnowska, and Wolfgang Gaißmaier with conducting the studies. We would also like to thank Tamara Herz for carefully editing the manuscript.

(c) 2008 Psychology Press, an imprint of the Taylor \& Francis Group, an Informa business http://www.psypress.com/edp

DOI: $10.1080 / 17405620801969585$ 
to happiness and well-being (e.g., Emmons, 1996; Klinger, 1977; Little, 1989). As Albert Einstein said, "If you want to live a happy life, tie it to a goal". This view emphasizes the importance of linking one's life and actions to the achievement of certain outcomes. However, it stands in contrast to an equally popular view emphasizing the process of goal pursuit. As a Buddhist proverb says, "The path is the goal." The research reported here revolves around this distinction between the process and outcome focus of personal goals. It addresses two central research questions: (a) what factors determine whether people focus more on the outcome of a goal or on the process of pursuing a goal? and (b) are process and outcome focus equally beneficial with respect to goal achievement?

Goals have been defined as cognitive representations of personally desired (or dreaded) states to be approached or avoided (e.g., Kruglanski, 1996), such as becoming a nurse or not becoming like one's parents. Goals direct attention, motivate and organize behaviour over time and across situations, and provide a sense of direction and purpose in life (Freund, 2006a). Moreover, research suggests that goal pursuit enhances performance (e.g., Austin \& Vancouver, 1996; Emmons, 1996; Freund, 2006b).

Not all goals, however, are created equal (Ryan, Sheldon, Kasser, \& Deci, 1996). They may differ in content, concreteness, difficulty, time frame, gain and loss orientation, and so forth (e.g., Little, 1989; Locke \& Latham, 2002; Wiese \& Freund, 2005). There is abundant empirical evidence that such characteristics affect the adaptiveness of goals (e.g., Freund, 2006a; Freund \& Ebner, 2005; Little, 1989; Locke \& Latham, 2002; Riediger \& Freund, 2004; Wiese \& Freund, 2005). Comparatively little, however, is known about age-related differences in the characteristics and functions of personal goals. This is surprising given the increasing interest in the active role that adults play in shaping their development (e.g., Baltes, Lindenberger, \& Staudinger, 2006; Brandtstädter, 1998; Freund, Li, \& Baltes, 1999; Lerner \& Busch-Rossnagel, 1981) and recent evidence suggesting that personal goals may be among the phenomena that show positive development throughout adulthood (Bauer \& McAdams, 2004; Riediger, Freund, \& Baltes, 2005; Sheldon \& Kasser, 2001). In the present research, we took a developmental perspective to investigate adult agerelated differences in outcome and process goal focus.

In Gestalt psychological terms, goal focus refers to those aspects of a goal that form a "figure" because they are more salient. Various dimensions of goal focus have been distinguished, such as gain-loss (e.g., Freund \& Ebner, 2005), intrinsic-extrinsic (e.g., Deci, Koestner, \& Ryan, 1999; Krapp, 2005), and mastery-performance (e.g., Dweck \& Leggett, 1988). The present research centred on the distinction between outcome and process goal focus (e.g., Sansone \& Thoman, 2005). Outcome focus refers to the cognitive representation of a goal primarily in terms of the outcome of goal pursuit, 
that is, the short- or long-term consequences of goal pursuit. Process focus refers to the cognitive representation of a goal primarily in terms of the process of goal pursuit, that is the means of and one's investment in goal attainment. For instance, one might represent the goal to start exercising regularly primarily in terms of its consequences (i.e., the outcome) such as weight loss or improvement in health - or primarily in terms of aspects of the goal-pursuit process, for example, the specific type of exercise (e.g., aerobics or jogging) or with whom one wants to exercise. Most goals are likely represented to some degree in terms of both, means and ends, process and outcome, but people may differ with respect to goal focus preference. The questions we address in this paper concern whether there are systematic individual differences in preference for outcome and process focus and whether goal focus is related to measures of goal engagement, goal achievement, and, more generally, adaptiveness in terms of affective wellbeing.

Below, we will specify the concept of process/outcome goal focus by distinguishing it from two related constructs, namely extrinsic/intrinsic motivation and performance/mastery orientation. Following that, we will discuss the theoretical background of our central predictions concerning age-related differences in, and the adaptiveness of, process and outcome focus. We will then introduce a specific goal context for one of the studies, namely, starting to exercise regularly.

Linking outcome and process focus to the concept of extrinsic and intrinsic motivation. Extrinsic motivation has been defined by a focus on the external consequences of goal achievement (e.g., external rewards for achieving a certain goal), whereas intrinsic motivation has been characterized by a focus on the task at hand (e.g., enjoyment of or interest in the goalrelevant activity). As compared to extrinsic motivation, intrinsic motivation is associated with voluntary involvement, more interest, and higher persistence in a task (e.g., Deci et al., 1999; Krapp, 2005; Lepper, 1981). Intrinsic motivation implies that a person focuses on the satisfaction derived from an activity rather than on the external consequences of goal achievement. For instance, when one's goal is to paint a picture, either the amount of money the picture will bring in at the next exhibition (i.e., extrinsic motivation) or the enjoyment of and interest in the activity of painting (i.e., intrinsic motivation) could be in the foreground. Engaging in goal pursuit for tangible, external rewards has been shown to undermine intrinsic motivation (Deci et al., 1999).

At first glance, the definitions of intrinsic and extrinsic motivation overlap those of process and outcome focus. Intrinsic motivation entails a focus on the process, extrinsic motivation on the consequences of attaining a certain outcome. The opposite, however, is not true: Both process and 
outcome focus can be either extrinsically or intrinsically motivated. For example, a person might focus on the outcome of goal pursuit (e.g., a beautiful painting) for an intrinsically motivated goal (e.g., aesthetic enjoyment) that was set autonomously and will have no further consequences such as praise or tangible rewards. Similarly, a person might focus on the process of goal pursuit (e.g., painting) because she/he is externally motivated to do so (e.g., through teachers' praise for her/his talent and perseverance).

Linking outcome and process focus to the concept of performance and mastery orientation. The literature on performance and mastery orientation is also relevant to the concept of process and outcome goal focus. Dweck (e.g., Dweck \& Leggett, 1988) defined "performance goal orientation" as a focus on how well one is doing (particularly as compared to others) and "mastery goal orientation" as a focus on learning and mastering a skill. She traced these two types of goal orientation back to beliefs about skills as fixed (i.e., an entity) or malleable (i.e., incremental), respectively. In the first case (entity theory), performance is seen as an indicator of underlying ability and provides feedback about an unchanging trait. In the latter case (incremental theory), feedback is a means of improving one's skill level. A number of studies in educational settings have shown that setting mastery goals promotes interest in and enjoyment of goal pursuit, but that performance goals are associated with a higher level of performance (e.g., Harackiewicz, Barron, Trauer, Carter, \& Elliot, 2000; see Dweck \& Molden, 2005 , for a recent review). In studies of organizational behaviour, however, VandeWalle and colleagues have shown a positive link between mastery goals (in this context often labelled "learning" goals) and the successful acquisition of new skills, feedback seeking, and performance (e.g., VandeWalle, 2001; VandeWalle, Brown, Cron, \& Slocum, 1999).

Seijts and Latham (2005) posited that the adaptiveness of mastery/ learning and performance orientation depends on whether the means and strategies of goal pursuit have already been learned and mastered: If they have not, learning goals should enhance performance because attention is focused on the means of goal pursuit while focusing on performance might actually distract and hinder successful goal-pursuit. In a similar vein, and using the terminology of process and outcome focus, Zimmerman and Kitsantas $(1997,1999)$ point out that, when learning to master a new task, people are more likely to adopt a process focus, defined by these authors as a focus on the acquisition of (strategic) skills (i.e., mastering the various elements and steps of a complex skill such as writing or dart throwing) or, in other words, on the means for achieving a given outcome. Outcome focus, in contrast, presupposes mastery of the different elements of which a complex skill is comprised and denotes a focus on the actual outcome (i.e., performance level). In line with Seijts and Latham (2005), Zimmerman 
and Kitsantas $(1997,1999)$ found that a focus on the acquisition of skills and means (i.e., process focus) is beneficial when learning a new skill whereas outcome focus enhances performance when the means need to be implemented as an integrated whole in the service of goal attainment.

In short, there are specific manifestations of outcome and process goal focus that have received considerable attention in educational and organizational settings. Currently, however, relatively little is known about the relevance of process and outcome goal focus in other domains. In addition, to our knowledge, no research has ever investigated the possibility of age-related differences in adults with respect to process and outcome goal focus. The present study aimed to extend previous research in these two respects by investigating outcome and process focus in the context of the goal to start exercising regularly in younger as compared to older adults.

\section{A developmental perspective on goal focus}

We posit that two factors associated with chronological age might contribute to the adoption of process versus outcome goal focus. Goals related to a temporally enduring state or to the maintenance of performance (e.g., "I want to stay healthy") require constant work on the goal and might thereby lend themselves more easily to a process focus than goals involving the achievement of new outcomes or benefits (e.g., "I want to be able to fit into this dress and wear it to the prom"). Similarly, as elaborated by construal level theory (Trope \& Liberman, 2003), goals that are temporally distant are more likely to invoke an outcome focus, whereas those that are temporally closer should lead to a stronger process focus. Preference for an outcome or process goal focus might thus vary depending on (a) the tendency to frame goals primarily in terms of acquiring new benefits versus maintaining the status quo and (b) their time perspective, both of which are related to age. With increasing age, time perspective decreases (Lang \& Carstensen, 2002) and framing goals in terms of maintenance increases (Ebner, Freund, \& Baltes, 2006). On the basis of these findings, we hypothesized that process focus would increase and outcome focus would decrease during adulthood.

Alternatively, however, one could also formulate the opposite hypothesis: Given that the future time perspective of older adults is shorter, they might find it more important to focus on tangible outcomes than on the continuous process of working towards a goal. Another argument for this alternative prediction comes from organizational research, which suggests that the adoption and adaptiveness of goal focus depends on skill level (Zimmerman \& Kitsantas, 1997, 1999), which, in turn, is often associated with age. In many domains of life, young adults are still in the process of 
acquiring the means and skills relevant for goal pursuit, such as the skills or knowledge needed in the professional/work domain or that needed to establish a long-term partnership and family. This might force young adults to focus more closely on the acquisition of skills or the process of goal pursuit. Middle-aged and older adults are more likely to have acquired most of the skills necessary to pursue their goals in both the work and the social domain and, thus, may be more likely to focus on the outcome of goal pursuit. Moreover, as Kanfer and Ackerman (2004) pointed out, skills can also be defined in terms of the balance between investment of resources and payoff. In the context of work-related motivational development during adulthood, they argued that the payoff for resource investment decreases with age, leading younger adults to be more focused on the process of resource investment and older adults to be more focused on the outcome.

In sum, different literatures support opposing hypotheses regarding agerelated differences in the extent of process and outcome goal focus. One purpose of the present study was to clarify which of these two alternative hypotheses is empirically supported in the context of the goal to start exercising regularly.

\section{Adaptiveness of process and outcome focus}

As mentioned above, in the skill-acquisition domain, the adaptiveness of goal focus has been proposed to vary with learning phase. Seijts and Latham (2005) posited that as long as the means and strategies of goal pursuit are not (yet) known or mastered, learning goals (as a manifestation of a process goal focus) should enhance performance because attention is focused on the means of goal pursuit, while focusing on performance (as a manifestation of outcome goal focus) might distract and thus hinder successful goal pursuit (see also Zimmerman \& Kitsantas, 1999). But how do outcome and process focus affect goal pursuit and subjective well-being in other goal domains that are not related to the acquisition of new skills?

One could argue that a strong and pervasive outcome focus fosters performance and goal achievement by providing clear criteria for judging whether the means are appropriate for achieving a given goal (Carver \& Scheier, 1995). However, we propose that, in the long run, outcome focus might be detrimental to goal engagement and subjective well-being because outcome orientation focuses attention on the discrepancy between the actual and the goal state (outcome), which might result in negative affect and selfregard. Moreover, achieving a desired outcome often does not result in enduring satisfaction because there are always new (better) desired outcomes (e.g., a fancier car, a bigger house). Thus, outcome focus might lead to a "treadmill effect" in that satisfaction related to the attainment of one goal is 
soon offset by the need to achieve new goals (e.g., Loewenstein \& Schkade, 1999).

In contrast, process focus should promote more enduring engagement in goal pursuit, goal satisfaction, and subjective well-being when the very pursuit of a goal is positively valued. Process focus might offer opportunities for positive rewards throughout the entire process of goal pursuit and setbacks might therefore be experienced as less detrimental and frustrating (Locke \& Latham, 2002).

We therefore hypothesized that, independent of a person's age, outcome focus would be related to lower levels of involvement and satisfaction with a goal as well as with lower optimism about reaching the goal, whereas process focus would be associated with higher levels of involvement and satisfaction with a goal as well as optimism about reaching the goal.

\section{Overview of the studies}

We conducted three studies to investigate the proposed age-related differences in goal focus in younger and older adults. Studies 1 and 2 were Internet-based studies assessing the preference for process versus outcome focus. Study 2 also included a "thinking exercise", which focused attention either on the process or the outcome of pursuing a goal and a subsequent measure of positive and negative affect, which allowed us to test for age differences in the consequences of goal focus. Study 3 addressed the question of age-related differences in goal focus in an everyday context, namely, in the context of pursuing the goal to start exercising regularly. We chose this context because starting to exercise regularly is a relatively frequent goal that is potentially relevant for both younger and older adults and thus suitable for a comparison of age groups (which can be difficult because younger and older adults often differ in the goals they pursue). Furthermore, process and outcome focus can be assessed easily by means of an evaluation of the participants' reasons for exercising. Individuals might focus primarily on the outcomes associated with regular exercise (e.g., more defined muscles, weight loss) or they might focus more on the activities and means involved in the process of exercising (e.g., enjoying the physical activity, getting together with friends to exercise).

\section{STUDY 1: PREFERENCE FOR PROCESS VERSUS OUTCOME FOCUS}

The main purpose of Study 1 was to test the hypothesis that there are agerelated differences in goal focus. To our knowledge, no prior research has directly assessed goal focus. Therefore, in Study 1, we also aimed to develop a method of assessing goal focus. 


\section{Method}

\section{Sample}

Participants were recruited via advertisements in Swiss Internet forums (e.g. seniors' forums, University of Zurich students' forums). Advertisements included a link to an online questionnaire, which was created and published using an online questionnaire tool (Surveymonkey; see www.surveymonkey.com). The sample consisted of 23 young adults (19-25 years, $M=22.12$, $S D=0.49 ; 75 \%$ female; all students) and 20 older adults (57-78 years, $M=65.90, S D=6.49 ; 65 \%$ female; $50 \%$ with a college degree, $15 \%$ retired).

\section{Measures}

Participants first responded to basic demographic questions about their age, sex, and occupational status, and then to items on a measure of goal focus. This measure was modelled after Vallacher and Wegner's (1989) questionnaire, which assesses level of action identification. More specifically, four goals (e.g., to quit smoking) were presented to participants, one goal at a time. Each goal was described by ten statements, half of which described the goal in terms of a means of achieving it (i.e., process-related statements, e.g., throw away cigarettes, spend time with non-smokers), the other half in terms of outcomes (i.e., outcome-related statements, e.g., save money, improve health). For each goal, participants were to select five of the ten statements that, in their opinion, best described the goal. The dependent variable was participants' process orientation as indexed by the mean number of process-related statements selected per goal (maximum 5) over the four goals $(M=2.12, S D=1.12)$. Cronbach's alpha for number of process-related statements selected across the four goals was .79 .

\section{Results and discussion}

As predicted, the older adults showed greater process orientation (and, thus, less outcome orientation) than the younger adults did (see Figure 1). In addition, whereas the younger adults selected more outcome- than processoriented goal descriptions, the older adults showed no such tendency. Univariate ANOVA revealed a significant main effect of age group on the mean number of process-related statements selected per goal $F(1,41)=5.41, p=.025$.

The results of Study 1 provide initial evidence for age-related differences in preference for representing goals in terms of the goal-pursuit process as opposed to the outcome. Unlike older adults, younger adults showed a clear preference for outcome-related goal descriptions. As this is the first study addressing the question of age-related differences in goal focus, this finding 


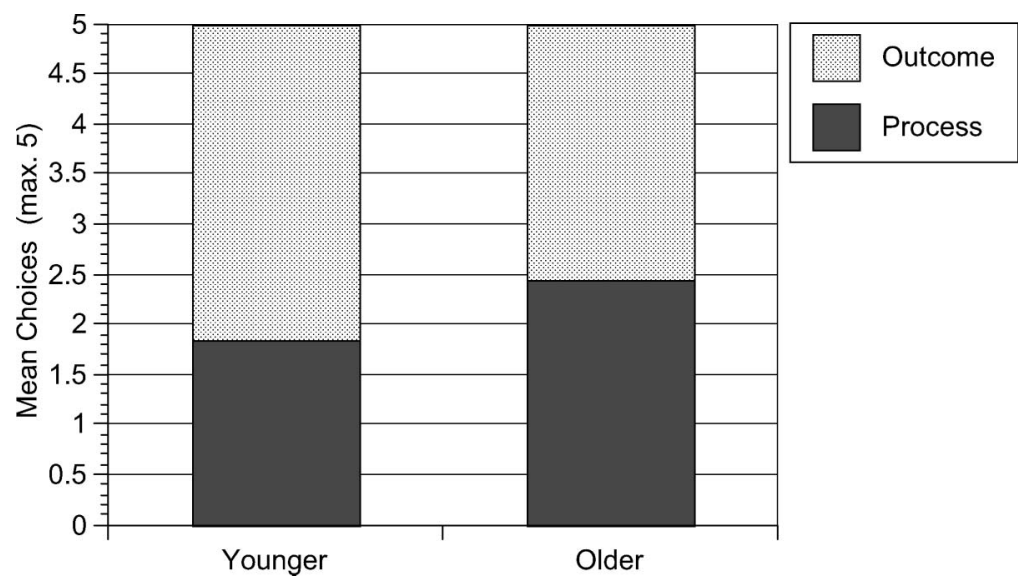

Figure 1. Selected goal focus as a function of age (means; study 1).

needs to be replicated in order to ensure its robustness. Moreover, Study 1 did not address the question of the possible consequences of adopting a process or an outcome focus. Therefore, Study 2 included indicators of affective well-being after participants had focused their attention on the goal-pursuit process versus the outcome.

\section{STUDY 2: EFFECTS OF GOAL FOCUS ON POSITIVE AND NEGATIVE AFFECT}

\section{Methods}

\section{Procedure}

Participants were recruited via advertisements on various German and Swiss web pages and asked to follow the link to an online questionnaire. In the questionnaire, participants first responded to basic demographic questions concerning their age, sex, and occupational status, and then, on a 7-point scale, to two items concerning their general life satisfaction. Afterwards, they selected one of two "thinking exercises", one focusing on the means (process choice), one focusing on the consequences of certain actions (outcome choice; see the appendix for English translation of Germanlanguage instructions). Participants subsequently filled out a questionnaire on positive and negative emotions. This allowed us to examine whether process and outcome focus have differential emotional consequences for younger and older adults. As a token of our appreciation for their 
participation in the study, we raffled off 10 gift vouchers for a book or movie tickets (worth approximately \$27).

\section{Sample}

All participants who fell within the pre-defined age groups of young (18 to 23 years) or older adults ( $>60$ years) were included in the sample. This criterion resulted in 87 participants, with 47 younger adults $(M=21.49, S D=1.64$; $85 \%$ female, $53.2 \%$ students) and 40 older adults (60-88 years, $M=69.58$, $S D=5.71 ; 43 \%$ female, $45 \%$ with a college degree, $72.5 \%$ retired).

\section{Measures}

Preference for process versus outcome focus. To assess preference for process versus outcome focus, we asked participants to read introductions to two different "thinking exercises": the introduction to Exercise A centred around ways of pursuing a goal, calling to mind that people pursue goals in different ways (process focus); that to Exercise B centred around the potential benefits of achieving a goal, calling to mind that people pursue goals for specific reasons (outcome focus). After reading the introductions, participants were asked to decide whether they wanted to do "Thinking Exercise A" ("which is about how we do the things we do") or "Thinking Exercise B" ("which is about why we do the things we do"). The dependent variable was the selection made (Exercise A or B), which indicated the participant's preference for focusing attention on the goal-pursuit process (A) or the outcome (B).

Process versus outcome focus exercise. Participants performed the exercise they had selected. Those who selected the process-focus exercise were to list two successive means by which one could attain the goal of having a good vacation. Those who selected the outcome-focus exercise were to list two successive reasons one could have for having a good vacation. This exercise was modelled after a manipulation used by Freitas, Gollwitzer, and Trope (2004) to induce either an abstract or concrete mindset.

Positive and negative affect. As a measure of current affect, the Positive and Negative Affect Schedule (PANAS; Watson, Clark, Tellegen, 1988) was administered. The PANAS consists of 10 positive and 10 negative emotion adjectives. On a scale ranging from 1 (not at all) to 7 (very much), participants indicated how well each of the adjectives described their current feelings. Scores for positive and negative affect were obtained by averaging the respective items. Cronbach's alpha for positive affect was $.86(M=4.54$, $S D=1.01)$, for negative affect $.81(M=1.89, S D=0.84)$. 
Before the "thinking exercises" were presented, a single item was used to assess life satisfaction as an indicator of general well-being (7-point scale, $M=5.37, S D=1.37$ ).

\section{Results and discussion}

Preference for outcome versus process focus. Replicating Study 1, a majority of the younger adults (29 of 47, or 61.7\%) selected the outcomefocused "thinking exercise"; this difference was marginally significant, $\chi^{2}(1)=2.47, p=.06$. The older adults showed no preference for either type of exercise (50\% selected the outcome-, $50 \%$ the process-focused exercise); this difference was not significant, $\chi^{2}(1)=0.27, p=.19$.

Affective consequences of goal focus. A 2 (Goal Focus: process vs. outcome focus; between-subjects factor) $\times 2$ (Age Group: young vs. old; between-subjects factor) ANOVA was conducted with positive and negative affect as dependent variables. In order to control for general well-being, life satisfaction was used as a covariate. To control for possible gender-related differences, sex was also included as a covariate.

As predicted, performing the outcome-focused exercise elicited marginally lower positive affect $(M=4.41, S D=0.96)$ than performing the processfocused exercise $\operatorname{did}(M=4.71, S D=1.07), \quad F(1,81)=1.82, \quad p=.09$, one-tailed. The main effect of goal focus on positive affect was qualified by a significant interaction with age group, $F(1,81)=3.52, p=.03$, onetailed. Follow-up analyses showed that, for older adults, the process-focused exercise was followed by significantly higher positive affect $(M=5.07$, $S D=0.72)$ than the outcome-focused exercise was $(M=4.32, S D=1.10)$, $F(1,38)=6.51, p=.008$. For younger adults, there was no such difference, $F(1,45)=0.32, p>.25$.

There was no significant main effect of goal focus on negative affect (process focus: $M=1.78, \mathrm{~S} D=0.80$; outcome focus: $M=1.96, S D=0.87$ ), $F(1,81)=0.59, p>.20$, one-tailed. There was, however, a marginally significant interaction with age group, $F(1,84)=2.61, p=.06$. Follow-up analyses revealed that performing the outcome-focused exercise led to slightly higher negative affect in younger adults $(M=2.16, S D=0.86)$ than in older adults $(M=1.67, S D=0.81), F(1,38)=1.33, p=.13$. As for the process-focused exercise, there was no such difference between younger $(M=1.86, S D=0.85)$ and older adults $(M=1.71, S D=0.77), F(1,38)=$ $0.84, p=.43$.

Although failing statistical significance, the pattern of frequencies of participants choosing to perform an outcome- over a process-focused exercise were in the same direction as the results of Study 1 regarding a preference for outcome- or process-focused goal descriptions. Younger adults showed a clear 
preference for outcome focus and selected the process-focused exercise less frequently than older adults did. As this pattern is not statistically significant, however, further studies were needed to determine whether the effect of Study 1 could be replicated with another sample using a different operationalization of goal focus. This was one of the aims of Study 3.

The main goal of Study 2 was to investigate the affective consequences of goal focus. We predicted that process focus would be more likely to be associated with emotional well-being than outcome focus would. Overall, the results confirmed our hypothesis. Focusing on the means of achieving a goal (process-focused "thinking exercise") was related to higher subsequent positive affect than focusing on the outcomes was. ${ }^{1}$ Interestingly, as indicated by an interaction of age and goal focus, this effect held only for older adults, while younger adults showed no such differences. For younger adults, outcome focus - although more preferred - was related to higher subsequent negative affect. It seems, then, that younger adults do not only not profit - but are even harmed-by adopting their preferred outcome focus, while older adults profit by adopting their preferred process focus. One possible interpretation of this pattern is that younger adults experience a mismatch between their habitual (outcome) focus and the process focus adopted to perform a given exercise; this mismatch might counteract the positive effects of process focus that older adults experience. Younger adults might also more acutely experience the negative effects of outcome focus because their attention is usually constantly focused on the negative discrepancy between actual and goal state, this attention being due to their developmental tasks, which entail achieving certain outcomes (such as getting an educational degree, finding a job, selecting a partner). This interpretation is highly speculative and potential age-related effects on goal focus require further testing. As a further step in this direction, Study 3 included the effects of goal focus on affective well-being and on goal-relevant variables such as perceived distance from the goal.

\section{STUDY 3: GOAL FOCUS IN THE CONTEXT OF A REAL-LIFE GOAL}

The main purpose of Study 3 was to replicate and extend the results of the first two studies in the context of a personal goal that younger and older

\footnotetext{
${ }^{1}$ Given that the conditions were randomly assigned, pre-existing individual differences in mood should be randomly distributed across the experimental groups and post-manipulation differences can be attributed to goal focus with some confidence. Moreover, controlling for general subjective well-being assessed before the manipulation should add to controlling for preexisting, trait-like individual differences in well-being that are correlated with positive and negative affect (in the case of this study, pre-manipulation well-being was correlated with postmanipulation positive affect $r=.27, p=.001$, and with negative affect $r=-.38, p<.001$ ).
} 
adults pursue in everyday life. As the target goal, we chose starting to exercise regularly because this is a relatively frequent goal of potential relevance for both younger and older adults. Holding goal content constant across age groups makes comparisons of goal focus across age groups easier than comparing goals that might differ in many other respects besides goal focus. Another reason for choosing the goal to begin exercising regularly was that outcome and process focus can be operationalized by evaluating the reasons for exercising (e.g., wanting to lose weight or reduce flabbiness as outcomes of exercising vs. enjoying the physical activity or getting together with friends for exercising as process-related aspects of exercising).

Study 3 involved two measurement points approximately four months apart. This design allowed us to investigate the effect of goal focus on change in specific goal dimensions. We chose the interval of four months because a substantial number of beginners quit exercising after a few weeks or months (Wagner, 1999). Therefore, the first few months after starting to pursue the goal of exercising regularly should be particularly informative as regards individual differences influencing one's adherence to the pursuit of this goal.

\section{Method \\ Procedure}

The study consisted of two assessment sessions with an average interim of 4.2 months $(S D=0.48)$. At each session, participants completed a set of questionnaires in small groups. At T1, participants were informed about the procedure of the study and signed an informed consent form. They then filled out a short demographic questionnaire and rated the goal of starting to exercise regularly on a number of dimensions. At T2, participants again rated their exercise goals and, in addition, reported how intensively they had exercised since $\mathrm{T} 1$ and whether they had given up pursuing the goal. At both assessment sessions, participants were also presented with a number of additional instruments that are not relevant here. At the end of each session, participants were debriefed, thanked, and received reimbursement (approximately \$20).

\section{Sample}

Participants were from a larger sample recruited from 28 sports facilities in Berlin, namely, from 14 fitness centres, three sports clubs, three university sports programmes, and eight other public institutions offering sports classes with trainers (e.g., seniors' centres). The requirements for initial recruitment were that the person: (a) was about to begin or had recently begun a sports activity at one of the above sports facilities; (b) had not 
regularly engaged in that sports activity for at least nine months; and (c) was either between 19 and 35 years or over 55 years of age. About one third of the initial sample was recruited through posters and brochures distributed in the cooperating sports facilities (with information on the study, participation requirements, and contact persons). The majority of the initial sample was recruited in person at the end of exercise classes and at registration sites of university sports programmes. Recruitment took five months, from September 1999 to January 2000. In the analyses reported in this paper, we have included only those participants of the initial sample that were comparable in age to the participants in Studies 1 and 2. Thus, 55 younger (19-25 years, $M=22.4, S D=1.5$ ) and 46 older (55-78 years, $M=63.8$, $S D=5.1)$ adults were included. Of this sample $75 \%$ was female. As for highest level of education completed, $10.9 \%$ of the participants had graduated from junior high school (8th grade); $22.8 \%$ from secondary school level I (10th grade), and $57.4 \%$ from senior high school (12th or 13th grade), and $8.9 \%$ of the sample held a university degree.

\section{Instruments}

Personal Goals (T1). At T1, participants used a 7-point scale to rate their goal of starting to exercise regularly on the following dimensions: (1) perceived distance to goal $(M=-5.05, S D=1.45)$; (2) perceived attainability $(M=5.64, S D=1.02)$; (3) goal involvement $(M=4.15, S D=0.75)$; (4) goal importance $(M=5.05, S D=1.29)$; and (5) goal satisfaction $(M=5.24, S D=1.27)$.

Goal Focus (T1). Process and outcome goal focus were operationalized using two subscales derived from a scale by Silberstein, Striegel-Moor, Timko, and Rodin (1988) for assessing motives to exercise. Process focus was assessed by three items measuring enjoyment using a 5-point response scale (exercising in order to meet new people, to socialize with friends, to have fun; Cronbach's alpha $=.68 ; M=3.48, S D=0.88$ ). Outcome focus was indexed by averaging across seven items assessing attractiveness, tone, and weight control (exercising in order to slim down, lose weight, improve one's appearance, redistribute weight, become more sexually desirable/attractive; Cronbach's alpha $=.78 ; M=2.98, S D=0.92$ ). Process and outcome focus were uncorrelated $(r=.07, n s)$, indicating that, using this operationalization, process and outcome focus constitute independent constructs rather than opposite poles of a single dimension.

Goal Pursuit (T2). At T2, participants again rated their exercise goal on the five dimensions mentioned above: (1) perceived distance to goal $(M=-5.22, S D=1.5)$; (2) perceived attainability $(M=5.64, S D=1.02)$; 
(3) goal involvement $(M=4.15, S D=0.75)$; (4) goal importance $(M=5.05, S D=1.29)$; and (5) goal satisfaction $(M=5.24, S D=1.23)$. In addition, as indicators of goal pursuit, participants rated their exercise adherence using a 6-point scale by estimating (1) how frequently $(M=2.75, S D=1.1)$ and (2) how regularly $(M=3.49, S D=1.3)$ they had exercised since $\mathrm{T} 1$.

Positive and negative affect. As an indicator of global subjective wellbeing, we used Steyer, Schwenkmezger, Notz, and Eid's (1997) multidimensional affect-rating scale. This scale is comprised of a total of 24 adjectives assessing positive mood, ease, and alertness as dimensions with positive valence, and negative mood, restlessness, and fatigue as dimensions with negative valence, whereby each dimension is indexed by four adjectives. At T2, participants indicated how often they had experienced each emotion during the previous four months-i.e., since T1-on a 5-point rating scale ranging from 1 (very seldom) to 5 (very often). Subscale scores were calculated by summing the responses to the items of each of the six subscales. An aggregate score for positive affect was then computed by averaging the scores of the three subscales with positive valence $(M=13.8$, $S D=2.5$, Cronbach's alpha $=.91)$; an aggregate score for negative affect was computed by averaging the scores of the three subscales with negative valence $(M=10.4, S D=2.8$, Cronbach's alpha $=.89)$.

\section{Results}

In this section, we will first address age-related differences in goal focus and subsequently turn to testing the hypotheses regarding the adaptiveness of goal focus in terms of global subjective well-being and change in perceived goal attainability, distance, importance, involvement, and satisfaction, as well as self-reported goal pursuit (here, exercise adherence).

Age-related differences in goal focus. Using a 2 (Goal Focus: process vs. outcome; within-subject factor) $\times 2$ (Age Group: young vs. old; between-subjects factor) ANOVA revealed the predicted significant interaction of age and goal focus, $F(1,97)=5.74, p=.02$. As can be seen in Figure 2, younger adults reported higher outcome focus, $t(99)=2.84, p=.01$. However, the two age groups did not differ significantly in process focus, $t(99)=-0.57, p=.57$, for the goal to start exercising regularly. Probing further into the within-age-group differences in goal focus, follow-up analyses revealed that, whereas younger adults did not show a significant difference between process and outcome focus, $t(54)=1.32, p>.19$, older adults do report a significantly higher process than outcome focus, $t(45)=5.29, p<.001$. 


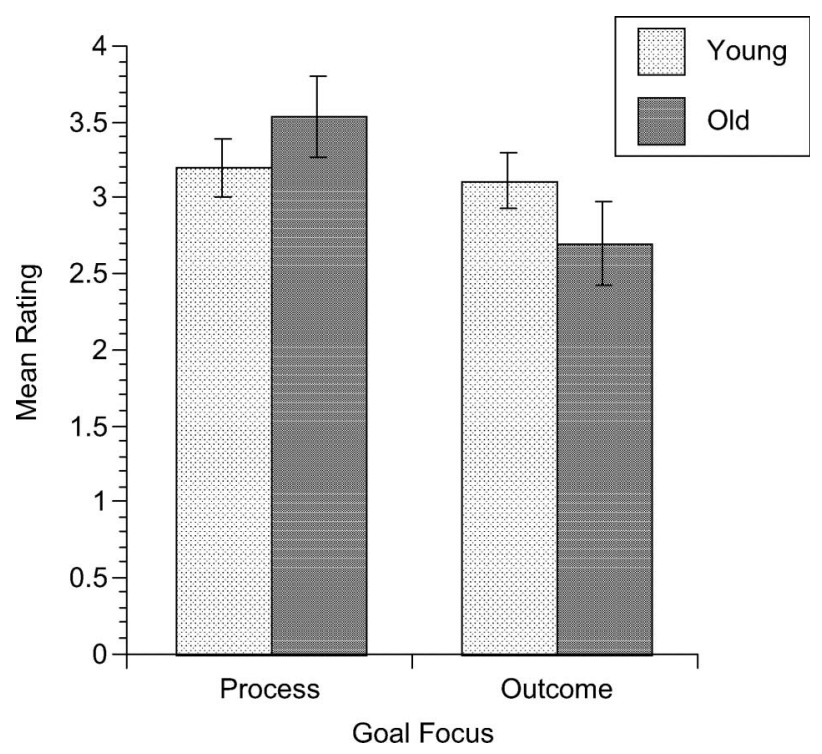

Figure 2. Goal focus as a function of age (means, 95\%-confidence intervals; Study 3).

Adaptiveness of goal focus. Before testing the influence of goal focus on the outcome variables included in the present study, we tested for agerelated differences. There was a non-significant tendency for older adults to report more positive emotions $\left(M_{\text {young }}=13.5, S D=2.19, \quad M_{\text {old }}=14.1\right.$, $S D=2.75), t(98)=1.26, p=.21$, and no age differences in self-reported negative affect $\quad\left(M_{\text {young }}=10.6, \quad S D=2.5 ; \quad M_{\text {old }}=10.1, \quad S D=3.2\right)$, $t(98)=0.96, p=.34$. Younger and older adults differed with respect to goal importance and involvement at $\mathrm{T} 1$, all $t(99)>0.61, p \leq .001$, with older adults showing higher values. There were no age differences regarding distance, attainability, and satisfaction with goal at T1, all $t(99)<0.28, p>$ .34. At T2, however, older adults showed higher scores on all of the goal variables, all $t(98)>2.7, p \leq .008$. Older and younger adults also differed with respect to self-reported frequency and regularity of goal pursuit (here, exercise frequency and regularity). As compared to the younger adults, older adults reported that they exercised somewhat more frequently $\left(M_{\text {young }}=2.56, S D=0.9, M_{\text {old }}=2.98, S D=1.2\right), t(98)=-2.0, p<.05$, and more regularly $\left(M_{\text {young }}=3.09, S D=132, M_{\text {old }}=3.99, S D=1.1\right)$, $t(98)=-3.67, p<.001$. To take these age-related differences into account, we included age by goal focus interactions when predicting the adaptiveness of goal focus as indexed by positive and negative affect, goal variables, and subjective exercise frequency and regularity (see below). 


\section{FREUND, HENNECKE, RIEDIGER}

Mirroring the results from Study 2, goal focus proved to be related to positive affect at T2 (see Table 1 for a summary of the regression analysis results). As expected, process focus at $\mathrm{T} 1 \mathrm{was}$ associated with positive affect at T2, whereas outcome focus at T1 was not. In Study 3, unlike Study 2, time-lagged predictions also showed that process focus was negatively related to negative affect. Again, outcome focus did not predict negative affect. There was no indication of an interaction of goal focus with age in predicting positive affect, $F_{\text {change }}(2,93)=0.80, p=.45$, or negative affect, $F_{\text {change }}(2,93)=1.38, p=.26$. These results are consistent with the assumption that process focus contributes to feeling good (and not bad), while outcome focus is not associated with subjective well-being.

In order to take individual differences in the goal variables at $\mathrm{T} 1$ into account, we examined how goal focus affects the change in the various goal variables. More specifically, to test the hypothesis that outcome focus is negatively related to measures of goal attainability, distance, importance, involvement, and satisfaction, a series of multiple regression analyses were conducted, regressing a goal measure of T2 on the respective goal measure at $\mathrm{T} 1$ as a first step, and then entering outcome and process focus as the second step, in order to obtain an estimate of the influence of goal focus on the change of goal measures over a period of four months. Table 2 presents a summary of the results of the regression analyses. In support of our hypotheses, goal focus was significantly related to all of the goal dimensions; after controlling for goal dimensions at T1, all $R_{\text {change }}^{2} \geq .03$, all $F_{\text {change }}(2,95)$ $\geq 2.17$, all $p s \leq .06$. As expected, process focus was positively related to change in all of the goal ratings. Specifically, process focus was associated with a decrease in perceived distance to the goal and increases in attainability, involvement, and satisfaction. Only partially confirming our hypotheses, outcome focus was unrelated to change in distance to the goal and attainability. Consistent with expectations, however, outcome focus was related to decreases in goal involvement and satisfaction. The relationship of

TABLE 1

Process but not outcome focus at T1 predicts positive and negative affect at T2 (results of regression analyses)

\begin{tabular}{lllc}
\hline Criterion T2 & \multicolumn{1}{c}{ Predictors T1 } & Beta & $R^{2}$ (model) \\
\hline Positive Affect & Outcome orientation & -.06 & \\
& Process orientation & $.29^{* *}$ & $.08^{* *}$ \\
Negative Affect & Outcome orientation & .02 & \\
& Process orientation & -.21 & $.04^{*}$ \\
\hline
\end{tabular}

Notes: Regression models were run including sex and education as control variables; neither variable significantly contributed to the prediction of affect. ${ }^{*} p<.05 ;{ }^{* *} p<.01$. 
TABLE 2

Longitudinal predictions of positive goal dimensions at T2 (controlling for T1) by process and outcome goal focus (T1): Results of regression analyses

\begin{tabular}{llcc}
\hline Criterion T2 & Predictors T1 Beta & Beta & $R^{2}$ (model) \\
\hline Distance to goal & Distance to goal T1 & -.15 & \\
& Outcome orientation & -.06 & $.15^{* *}$ \\
Attainability & Process orientation & $-.31^{* *}$ & $.51^{* *}$ \\
& Attainability T1 & -.05 & \\
& Outcome orientation & $.18^{*}$ & $.35^{* *}$ \\
Satisfaction & Process orientation & $.28^{* *}$ & \\
& Satisfaction T1 & $-.22^{*}$ & $.21^{* *}$ \\
Involvement & Outcome orientation & $.21^{*}$ & \\
& Process orientation & $.40^{* *}$ & $.23^{* *}$ \\
Importance & Involvement T1 & $-.18^{*}$ & \\
& Outcome orientation & $.19^{*}$ & $.28^{* *}$ \\
\hline
\end{tabular}

Note: $* p<.05 ; * * p<.01$.

goal focus was not moderated by age. There were no significant interactions of age with goal focus, all $R_{\text {change }}^{2} \geq .03$, all $F_{\text {change }}(2,91)<2.23$, all $p$ s $>.11$.

Regression analysis was also used to test whether goal focus at T1 was related to self-rated goal pursuit at T2 (again, controlling for sex and education). Results show, again as expected, that self-reported exercise frequency at T2 was predicted by process focus at T1 $(\beta=1.10, p<.01)$, but not by outcome focus at T1 $(\beta=-0.40, p=.27)$. There was a significant interaction of age and process focus $(\beta=-0.73, p<.01)$, but not for age and outcome focus $(\beta=0.34, p=.14)$. For the last step of entering the interaction terms, $F_{\text {change }}(2,93)=5.88, p<.01$.

Self-reported regularity at T2 was also predicted by process focus at T1 $(\beta=0.97, p<.05)$, but not by outcome focus at T1 $(\beta=-0.66, p=.15)$. There was a tendency for an interaction of age with process focus $(\beta=-0.52, p=.08)$, but not for outcome focus $(\beta=0.46, p=.12)$. For the last step of entering the interaction terms, $F_{\text {change }}$ was only marginally significant, $F_{\text {change }}(2,93)=2.75, p=.07$.

The beneficial effects of process focus on measures of goal pursuit, then, are to some degree dependent on age. Follow-up regression analyses conducted separately for younger and older adults showed that, contrary to our hypotheses, process focus was only beneficial for younger adults regarding exercise frequency, again controlling for education and sex $(\beta=0.393, p<.01), F_{\text {change }}(2,52)=4.95, p=.01$, but did not significantly 
predict exercise frequency in older adults after controlling for sex and education, $F_{\text {change }}(2,41)=2.18, p=.13$. The same pattern emerged for selfreported exercise regularity. Younger adults reported exercising more regularly when adopting a process focus, after controlling for education and sex $(\beta=0.28, p<.05), F_{\text {change }}(2,52)=3.3, p<.05$, whereas process focus failed to significantly predict how regularly older adults exercised, $F_{\text {change }}(2,42)=1.27, p=.29$.

Taken together, the results of this study show the expected age-related differences in goal focus: While older adults were more likely to be process focused in pursuing their exercise-related goal, younger adults focused more on the outcome. Regardless of age, process focus contributed longitudinally to positive goal evaluations such as goal satisfaction or subjective distance to the goal. Fitting into this pattern of results, process focus was associated with higher positive and lower negative emotions for both age groups. However, a look at outcomes more closely related to actual goal performance revealed that it was particularly the younger age group that profited from a process focus on their exercise-related goal. Younger but not older adults reported higher exercise frequency and regularity when adopting a process focus.

\section{GENERAL DISCUSSION}

The present paper presents, for the first time, converging evidence of agerelated differences in process and outcome goal focus from three studies using different operationalizations of goal focus. Study 1 investigated preference for goal focus in the description of goals either in terms of their means (process focus) or their consequences (outcome focus). Study 2 assessed goal focus as the selection of one of two exercises ("thinking exercises") that focus attention on either the means involved (process) or the related higher-order goals (outcomes). Finally, Study 3 used personal reasons for exercising to operationalize process and outcome focus. Across these different types of operationalization, the pattern of results-although not statistically significant in Study 2-suggests that younger adults show a preference for outcome over process goal focus and a lower process focus than older adults. For instance, in Study 3 younger adults reported a stronger focus on the outcome of their exercise goal (e.g., increased attractiveness) than older adults. Moreover, older adults reported a stronger focus on the process of goal pursuit (e.g., enjoying exercising) than on the outcome. This finding speaks against the hypothesis that older adults prefer to focus on tangible outcomes rather than on the continuous process of pursuing a goal. Note, that in the present study, the goal-starting to exercise regularly - was the same for younger and older adults. It is a goal that both age groups can achieve. Therefore, the age differences in goal focus found in the Study 3 cannot be attributed to differences in goals. 
Studies 2 and 3 addressed the question of whether outcome and process focus are differentially associated with goal-relevant outcomes. Both studies required online participation. Online studies are convenient for participants as they do not need to leave their home and come to the laboratory in the university to participate. For older adults, this might mean that even people who are somewhat limited in their mobility due to health-related reasons or feel nervous about coming to a university, can easily participate in a study. These factors might increase the heterogeneity of the sample compared to a traditional study taking place in a laboratory. At the same time, however, one could argue that using the Internet is not as common among older adults leading to increased sample selectivity. In fact, when investigating the age-distribution of samples of online studies, older adults are clearly underrepresented (Reips, 2001). Regarding other characteristics such as IQ distribution, however, online samples seem to be highly representative (Reips, 2001). It seems, then, that advantages and disadvantages of online versus laboratory testing might cancel each other out. As is typical for laboratory studies too, the online studies reported here used convenience samples and generalizability is based on replications and the use of different methodology rather than representative samples.

Study 2 provided initial evidence that process focus is related to positive affect, a finding that was replicated in Study 3. Contrary to Study 3, which did not reveal age-differential effects of goal focus on affect, Study 2 suggests that older adults might profit more from a process focus while younger adults might even be harmed when adopting an outcome focus. The two studies differ with respect to the relevance of the goal (not personally important in Study 2 vs. high personal importance in Study 3) as well as the time frame of these goals (minutes in Study 2, months in Study 3). Therefore, differences between these two studies might indicate the role of the kind of goal being pursued with a specific goal focus.

Going beyond affective consequences of goal focus, Study 3 showed that, regardless of age, process focus was associated with a decrease in the distance to the goal over time, increased attainability, importance, and satisfaction as well as higher goal involvement over a period of four months. Process focus was also positively related to measures of goal pursuit (selfreported exercise frequency and regularity). In contrast, outcome focus was not or even negatively related to measures of positive evaluation of the goal and goal pursuit. This pattern of results suggests that, at least in the context of the goal to start exercising regularly, process focus is more adaptive for various measures of subjective goal satisfaction and for goal pursuit. Interestingly, the positive effect of goal focus was not affected by age regarding subjective evaluations. Younger as well as older adults rated their goal to exercise regularly more favourably when adopting a process focus. Contrary to our hypotheses, however, younger adults profited more than 
older adults from a process focus with respect to measures of actual goal pursuit. Interestingly, then, in the context of exercise, younger adults are less likely to focus on the process although they profit particularly from such a focus for increasing goal-relevant behaviour (viz., exercising frequently and regularly). It might be the case that stepping outside the box of their more typical way of pursuing goals, namely by focusing on the outcome, motivates younger adults more strongly to actually do something for their goals than it does older adults, who are more likely to go about their goals by focusing on the process. This is merely speculative at this point and warrants further testing.

There are basically two complementary explanations for the age-related differences in goal focus. First, older adults may have learned through repeated experience that reaching goals, though important, leads to a hedonic treadmill that can only be counteracted by focusing on the process of goal pursuit instead of the consequences related to reaching one's goal. Second, having reached or surpassed one's personal asymptotic level in functioning, reaching new outcomes might become more and more difficult with increasing age. Focusing on the process instead of the outcome of a goal might help buffer against disappointment when not reaching the goal. In fact, attractiveness might be just one of these domains. Age differences might be less pronounced or even absent when considering a domain where younger and older adults do not differ regarding having reached the asymptote (see Ebner et al., 2006, for a similar approach for gain versus maintenance/loss orientation in goals). Further studies are needed to identify which of the factors associated with age-related differences contribute to an agedifferential goal focus. Given that older adults are more likely to adopt a process than an outcome focus, this might contribute to continued positive involvement with goals and general well-being. Future studies need to address the question of generalizability of goal pursuit to other life domains.

One of the shortcomings of Study 3 is the indirect operationalization of goal focus via motives to exercise. One might argue that the specific motives we used for operationalizing process and outcome focus are themselves agerelated. Wanting to work on losing or distributing weight might be a "young" motive for exercising, wanting to enjoy the work-out or doing something with friends could be seen as an "old" goal. We believe, however, that there is nothing inherently young in wanting to lose weight and nothing per se old in wanting to enjoy what one is doing. If these motives seem "young" or "old" to us, this might be the case because there is some socially shared expectation that younger adults are more outcome-focused in their goal pursuit than older adults, whom we might expect to be more processoriented. To the best of our knowledge, there is currently no data available addressing the question of age-related expectations about goal focus. Moreover, the pattern of results regarding the preference for goal focus and 
the affective consequences converges with the results of Studies 1 and 2 using very different operationalizations of goal focus.

In fact, one of the strengths of the present studies is that they involve different measures of goal focus, attesting to the robustness of findings across different modes of assessment and samples. While Studies 1 and 2 did not concern the participants' personal goals, Study 3 involved a minilongitudinal design in a real-life setting that was freely chosen by both age groups.

To our knowledge, the present studies are the first to demonstrate agerelated differences in process and outcome focus. As focusing on the process of goal pursuit seems to be more beneficial motivationally and emotionally, the stronger process focus in old age may be among the processes contributing to successful aging.

Manuscript received 23 February 2007 Revised manuscript accepted 2 January 2008 First published online 8 May 2008

\section{REFERENCES}

Austin, J. T., \& Vancouver, J. B. (1996). Goal constructs in psychology: Structure, process, and content. Psychological Bulletin, 120, 338-375.

Baltes, P. B., Lindenberger, U., \& Staudinger, U. M. (2006). Life span theory in developmental psychology. In R. M. Lerner (Ed.), Handbook of child psychology: Vol. 1. Theoretical models of human development (6th ed., pp. 569-664). Hoboken, NJ: Wiley.

Bauer, J. J., \& McAdams, D. P. (2004). Personal growth in adults' stories of life transitions. Journal of Personality, 72, 573-602.

Brandtstädter, J. (1998). Action theory in developmental psychology. In R. M. Lerner (Ed.), Handbook of child psychology: Vol. 1. Theoretical models of human development (5th ed., pp. 807-863). New York: Wiley.

Carver, C. S., \& Scheier, M. F. (1995). On the self-regulation of behaviour. Cambridge, UK: Cambridge University Press.

Deci, E. L., Koestner, R., \& Ryan, R. M. (1999). A meta-analytic review of experiments examining the effects of extrinsic rewards on intrinsic motivation. Psychological Bulletin, $125,627-668$.

Dweck, C. S., \& Leggett, E. (1988). A social-cognitive approach to motivation and personality. Psychological Review, 95, 256-273.

Dweck, C. S., \& Molden, D. C. (2005). Self-theories: Their impact on competence motivation and acquisition. In A. J. Elliot \& C. S. Dweck (Eds.), Handbook of competence and motivation (pp. 122-140). New York: Guilford Press.

Ebner, N. C., Freund, A. M., \& Baltes, P. B. (2006). Developmental changes in personal goal orientation from young to late adulthood: From striving for gains to maintenance and prevention of losses. Psychology and Aging, 21, 664-678.

Emmons, R. A. (1996). Striving and feeling: Personal goals and subjective well-being. In P. M. Gollwitzer \& J. A. Bargh (Eds.), The psychology of action: Linking cognition and motivation to behavior (pp. 313-337). New York: Guilford Press. 
Freitas, A. L., Gollwitzer, P., \& Trope, Y. (2004). The influence of abstract and concrete mindsets on anticipating and guiding others self-regulatory efforts. Journal of Experimental Social Psychology, 40, 739-752.

Freund, A. M. (2006a). Differentiating and integrating levels of goal representation: A life-span perspective. In B. R. Little, K. Salmela-Aro, \& S. D. Phillips (Eds.), Personal project pursuit: Goals, action and human flourishing (pp. 247-270). Mahwah, NJ: Lawrence Erlbaum Associates, Inc.

Freund, A. M. (2006b). Age-differential motivational consequences of optimization versus compensation focus in younger and older adults. Psychology \& Aging, 21, 240-252.

Freund, A. M., \& Ebner, N. C. (2005). The aging self: Shifting from promoting gains to balancing losses. In W. Greve, K. Rothermund, \& D. Wentura (Eds.), The adaptive self: Personal continuity and intentional self-development (pp. 185-202). Ashland, OH: Hogrefe \& Huber.

Freund, A. M., Li, K. Z. H., \& Baltes, P. B. (1999). Successful development and aging: The role of selection, optimization, and compensation. In J. Brandtstädter \& R. M. Lerner (Eds.), Action and self-development: Theory and research through the life span (pp. 401-434). Thousand Oaks, CA: Sage.

Harackiewicz, J. M., Barron, K. E., Trauer, J. M., Carter, S.. M., \& Elliot, A. J. (2000). Shortterm and long-term consequences of achievement goals: Predicting interest and performance over time. Journal of Educational Psychology, 92, 316-330.

Kanfer, R., \& Ackerman, P. L. (2004). Aging, adult development, and work motivation. Academy of Management Review, 3, 440-458.

Klinger, E. (1977). Meaning and void: Inner experience and the incentives in people's lives. Minneapolis, MN: University of Minnesota Press.

Krapp, A. (2005). Basic needs and the development of interest and intrinsic motivational orientations. Learning and Instruction, 15, 381-395.

Kruglanski, A. W. (1996). Goals as knowledge structures. In P. M. Gollwitzer \& J. A. Bargh (Eds.), The psychology of action: Linking cognition and motivation to behavior (pp. 599-618). New York: Guilford Press.

Lang, F. R., \& Carstensen, L. L. (2002). Time counts: Future time perspective, goals, and social relationships. Psychology \& Aging, 17, 125-139.

Lepper, M. (1981). Intrinsic and extrinsic motivation in children: Detrimental effects of superfluous social controls. In W. W. Collins (Ed.), Minnesota symposium on child psychology Vol. 14 (pp. 155-214). Hillsdale, NJ: Lawrence Erlbaum Associates, Inc.

Lerner, R. M., \& Busch-Rossnagel, N. A. (Eds.). (1981). Individuals as producers of their development: A life-span perspective. New York: Academic Press.

Little, B. R. (1989). Personal projects analysis: Trivial pursuits, magnificent obsessions, and the search for coherence. In D. M. Buss \& N. Cantor (Eds.), Personality psychology: Recent trends and emerging directions (pp. 15-31). New York: Springer.

Locke, E. A., \& Latham, G. P. (2002). Building a practically useful theory of goal setting and task motivation: A 35-year odyssey. American Psychologist, 57, 705-717.

Loewenstein, G., \& Schkade, D. (1999). Wouldn't it be nice? Predicting future feelings. In D. Kahnemann, E. Diener, \& N. Schwarz (Eds.), Well-being: The foundation of hedonic psychology (pp. 85-105). New York: Russell Sage Foundation.

Reips, U. (2001). The Web Experimental Psychology Lab: Five years of data collection on the Internet. Behavior Research Methods, Instruments, \& Computers, 33, 201-211.

Riediger, M., \& Freund, A. M. (2004). Interference and facilitation among personal goals: Differential associations with subjective well-being and persistent goal pursuit. Personality and Social Psychology Bulletin, 30, 1511-1523.

Riediger, M., Freund, A. M., \& Baltes, P. B. (2005). Managing life through personal goals: Intergoal facilitation and intensity of goal pursuit in younger and older adulthood. Journals of Gerontology: Psychological Sciences, 60B, P84-P91. 
Ryan, R. M., Sheldon, K. M., Kasser, T., \& Deci, E. L. (1996). All goals are not created equal: An organismic perspective on the nature of goals and their regulation. In P. M. Gollwitzer \& J. A. Bargh (Eds.), The psychology of action: Linking cognition and motivation to behavior (pp. 7-26). New York: Guilford Press.

Sansone, C., \& Thoman, D. B. (2005). Interest as the missing motivator in self-regulation. European Psychologist, 10, 175-186.

Seijts, G. H., \& Latham, G. P. (2005). Learning versus performance goals: When should each be used? Academy of Management Executive, 19, 124-131.

Sheldon, K. M., \& Kasser, T. (2001). Getting older, getting better? Personal strivings and psychological maturity across the life span. Developmental Psychology, 37, 491-501.

Silberstein, L. R., Striegel-Moore, R. H., Timko, C., \& Rodin, J. (1988). Behavioral and psychological implications of body dissatisfaction: Do men and women differ? Sex Roles, 19, 219-233.

Steyer, R., Schwenkmezger, P., Notz, P., \& Eid, M. (1997). Der mehrdimensionale Befindlichkeitsfragebogen (MDBF). Handanweisung [The multidimensional affect rating scale (MDBF). Manual]. Göttingen, Germany: Hogrefe.

Trope, Y., \& Lieberman, N. (2003). Temporal construal. Psychological Review, 110, 403-421.

Vallacher, R. R., \& Wegner, D. M. (1989). Levels of personal agency: Individual variation in action identification. Journal of Personality and Social Psychology, 57, 660-671.

VandeWalle, D. (2001). Goal orientation: Why wanting to look successful doesn't always lead to success. Organizational Dynamics, 30, 162-171.

VandeWalle, D., Brown, S. P., Cron, W. L., \& Slocum, J. W. (1999). The influence of goal orientation and self-regulation tactics on sales performance: A longitudinal field test. Journal of Applied Psychology, 84, 249-259.

Wagner, P. (1999). Aussteigen oder Dabeibleiben? Determinanten der Aufrechterhaltung sportlicher Aktivitaet von Erwachsenen in gesundheitsorientierten Sportprogrammen [Drop out or stick to it? Determinants of adults' adherence to health-oriented exercise programs]. Leipzig, Germany: Wissenschaftliche Buchgesellschaft/KNO.

Watson, D., Clark, L. A., \& Tellegen, A. (1988). Development and validation of brief measures of positive and negative affect: The PANAS scales. Journal of Personality and Social Psychology, 54, 1063-1070.

Wiese, B. S., \& Freund, A. M. (2005). Goal progress makes one happy, or does it? Longitudinal findings from the work domain. Journal of Occupational and Organizational Psychology, 78, 287-304.

Zimmerman, B. J., \& Kitsantas, A. (1997). Developmental phases in self-regulation: Shifting from process to outcome goals. Journal of Educational Psychology, 89, 29-36.

Zimmerman, B. J., \& Kitsantas, A. (1999). Acquiring writing revision skill: Shifting from process to outcome self-regulatory goals. Journal of Educational Psychology, 91, 241-250. 


\section{APPENDIX}

Introductions to the two "thinking exercises" used in Study 2.

\section{Thinking Exercise A (process focus)}

"We all pursue our goals in certain ways. We can examine our behaviour and its connection with general life goals. This is what we want to demonstrate to you with the following example: Most people pursue the goal of being physically active. How? Exercising regularly. How? Joining a sports club. As you can see, there are different ways in which we can try to attain our goals. Thinking exercise A focuses your attention on how one pursues goals."

\section{Thinking Exercise B (outcome focus)}

"For everything we do, there is always a reason why we do it. We can often trace our behaviour back to general life goals. This is what we want to demonstrate to you with the following example: Most people pursue the goal of getting some exercise. Why? To improve their health. Why? To just feel good in general. As you can see, there are different reasons why we behave in certain ways. Thinking exercise B focuses your attention on why we pursue certain goals." 